\title{
Trabalho e Quilombolas: As Relações de Trabalho dos Residentes no Quilom- bo São José da Serra - Valença/Rio de Janeiro
}

\section{Work and "Quilombolas": the working relations of people living in "Quilombo" São José da Serra - Valença - Rio de Janeiro}

Artigo
Original

Original

Paper

Daline Lopes

Áurea Dias ${ }^{2}$

Douglas Mansur ${ }^{3}$

Palavras-chaves:

Quilombo

Trabalho

Etnicidade

\section{Resumo}

O artigo trata das relações de trabalho no Quilombo São José da Serra no município de Valença/Rio de janeiro. Para tanto, faz-se necessário a apreensão da história, o sentido de territorialidade e demais elementos de afirmação étnica do quilombo; verificar impactos do processo de titulação sobre a vida dos quilombolas; identificar se há e como se dá a mobilização por demandas políticas e sociais. A categoria teórica fundamental é trabalho. Os instrumentos da pesquisa de campo são: observação participante, entrevistas não-estruturadas com ênfase na história de vida e trabalho.

\section{Abstract}

The article is about the relations of work in Quilombo São José da Serra, Valença, state of Rio de Janeiro, Brazil. For that, is necessary the full comprehension of the history, territoriality sense and the others elements of ethnic affirmation of the quilombo; to verify impacts of the process of titulation on the life of the quilombolas; to identify if exists and how is done the mobilization for political and social demands. The fundamental theoric category is work. The field research instruments are: inside observations and informal interviews with focus in the history of life and work of the quilombolas.

\section{Key words:}

Quilombo

Work

Ethnicity

\section{Introdução}

O interesse por essa temática surgiu de uma pesquisa preliminar (bibliográfica e de campo) sobre o quilombo São José da Serra (Valença/RJ), a qual permitiu-nos identificar que muitas das condições de trabalho desses quilombolas eram precarizadas, em grande parte, em decorrência do fato de não terem a posse legal da terra, entre outros aspectos a serem explorados por esta pesquisa. Desse modo, vendiam sua força de trabalho em condições informais, sem vínculos trabalhistas, a proprietários das fazendas nos arredores, como uma forma de garantirem alguma renda para subsistência. Tal condição de informalidade, no âmbito de uma sociedade de economia capitalista e regime de trabalho contratual, pode ser encarado de diversas formas por esse grupo específico, sendo de grande importância verificar os significados que o mesmo adquire para o grupo.

Outro fato motivador dessa pesquisa são as recentes conquistas no processo de titulação das terras pelo Quilombo São José da Serra. Desse modo, a reivindicada autonomia

\footnotetext{
${ }^{1}$ Acadêmica - Ciências Sociais Aplicadas e Humanas - Curso de Serviço Social - UniFOA

${ }^{2}$ Mestra - Ciências Sociais Aplicadas e Humanas - Serviço Social - UniFOA

${ }^{3}$ Doutor - Ciências Sociais Aplicadas e Humanas - Antropologia - UniFOA
} 
no uso da terra, por parte desta população quilombola torna este momento propício para se analisar quais os efeitos do acesso efetivo à terra para eventuais mudanças nas condições de vida dessas populações e, em particular, no tocante às condições de trabalho e seus significados.

Ao analisarmos criticamente a história dos africanos e seus descentes no Brasil, verificamos que esta não significou passividade e apatia, mas sim "luta" e organização. Nesse sentido, quando pensamos a situação dos escravizados e dos libertos, também temos que considerar o tipo de sociedade existente naquele momento e as possibilidades desses sujeitos diante de um contexto que não previa nenhum tipo de integração e inserção social, tanto dos escravizados como dos libertos, na sociedade dos homens livres. A esse processo de luta e organização negra existente desde a época da escravidão, podemos chamar de "resistência negra".

A "resistência negra" ocorreu de várias formas durante o período escravocrata: insubmissão às regras do trabalho nas roças ou plantações onde trabalhavam; revoltas; fugas; abandonos das fazendas pelos escravos; assassinatos de senhores e suas famílias; abortos; quilombos; organizações religiosas; danças; cantos; entre outras.

Os quilombos, uma importante forma de "resistência negra" ao regime escravocrata, foram duramente perseguidos durante todo o período colonial. Em 1740, o conselho Ultramarino, órgão colonial responsável pelo controle central patrimonial, considerava quilombo "toda habitação de negros fugidos que passem de cinco, em parte despovoada, ainda que não tenha ranchos levantados nem se achem pilões neles" (O'DWYER, 2002:47). Mesmo hoje, após centenas de anos, essa idéia distorcida de quilombo ainda permanece no imaginário da maior parte da sociedade. Insistir em tal conceito significa negar ou tornar invisível o verdadeiro sentido e a história dos quilombos.

Munanga e Gomes (2006) afirmam que os quilombos brasileiros podem ser considerados como uma inspiração africana, reconstruída pelos escravizados para se opor a uma estrutura escravocrata, e em busca da implantação de uma outra forma de vida, de uma outra estrutura política, na qual os oprimidos possam deixar de sê-lo.
Segundo Munanga e Gomes (2006) a palavra 'Kilombo' é originária da língua banto 'umbundo', falada pelo povo 'ovimbundo', que se refere a um tipo de instituição sociopolítica militar conhecida na África Central, mais especificamente na área formada pela atual República Federativa do Congo (antigo Zaire) e Angola.

Foram constituídos inúmeros quilombos no Brasil durante o séc. XIX, principalmente, nas décadas finais do período escravista. Seus habitantes eram chamados quilombolas, mocambeiros ou calhambolas e foram perseguidos pelos senhores de escravos e pelo aparato militar colonial e imperial onde quer que estivessem. Alguns quilombos conseguiram sobreviver durante muitos anos, mesmo durante a escravidão. A maioria dos sobreviventes foram aqueles que se localizavam em áreas de maior isolamento e outros que mantiveram relações de alianças com índios, brancos pobres e demais populações. Em alguns casos, essas duas estratégias podem ter acontecido ao mesmo tempo. Nesse sentido, quilombo não significava refúgio de escravos fugidos, tratava-se de uma organização fraterna e livre, com laços de solidariedade e convivência resultante do esforço dos negros escravizados de resgatar sua liberdade e dignidade por meio da fuga do cativeiro e da criação de uma sociedade livre.

O tamanho dos quilombos variava muito, desde acampamentos de alguns fugitivos, às povoações com milhares de moradores. Sendo assim, temos exemplos como o quilombo Grande Mineiro com aproximadamente mil pessoas e o quilombo dos Palmares em Alagoas com cerca de 30 mil pessoas.

Como já foi dito, muitos quilombos surgiram a partir da fuga dos escravos representando um caso "de etnogênese cuja consolidação como grupo social se deu com o estabelecimento de territórios autônomos no interior da Colônia e a posterior defesa desses territórios frente a ataques externos, sendo a República de Palmares o caso mais conhecido" (LITTLE, 2002:5). Além desse caso específico, ainda há outras origens para os quilombos:

(...) como base nos múltiplos casos históricos no Maranhão, o conceito de remanescentes das comunidades dos quilombos não deve ser restringido a casos de fuga, mas precisa incorporar o amplo leque de situações no qual, em vez de grandes deslocamentos 
por parte dos escravos, houve a apropriação efetiva das grandes propriedades que entraram em decadência ou faliram, assim 'aquilombando a casa grande' (LITTLE, 2002:6).

Little (2002) acredita que a sobrevivência dos quilombos durante séculos deve-se, em parte, à estratégia da invisibilidade simbólica e social, que foi empregada pelos quilombolas. Junto à invisibilidade está o aspecto da marginalidade econômica e de sua localização em áreas intersticiais dos centros econômicos. Esses aspectos e estratégias, devido aos fluxos de interesse do mercado capitalista por recursos naturais e mercadorias, vão perdendo seus significados e as terras dos quilombolas passam a estar na mira das forças econômicas dominantes.

O sistema repressor da classe dominante utiliza-se de suportes econômicos que variam de acordo com a época histórica e a dinâmica da economia, sendo assim, torna-se importante perceber a mudança na lógica da luta dos quilombolas. $\mathrm{Na}$ época da escravidão, onde o valor do escravo era significativo economicamente, os quilombolas lutavam por sua liberdade, independência e dignidade, esse fato mudou com a abolição da escravidão em 1888, quando os ex-escravos foram totalmente negligenciados pelo Estado e o interesse econômico que pairava sobre eles acabou. Com o decorrer dos anos o interesse econômico pelas terras onde os quilombolas tinham se estabelecido cresceu, obrigando seus descentes a lutarem pela posse das terras.

Entre os anos 70 e 80 do século $\mathrm{XX}$, o conceito de quilombo foi recolocado no contexto nacional de abertura política que inspirou revisões: da história nacional e regional; da descoberta das comunidades negras rurais e da constituição do movimento negro na atualidade. Nessa época, houve grandes mobilizações populares, em que estiveram envolvidos militantes do Movimento Negro Unificado, representantes de diversos quilombos, parlamentares negros, entre outros. Essas mobilizações tiveram seu ápice com o Art. 68 do Ato das Disposições Constitucionais Transitórias da Constituição Federal de 1988 que garantiu: "aos remanescentes das comunidades de quilombos que estejam ocupando suas terras é reconhecida a propriedade definitiva, devendo o Estado emitir-lhes os títulos específicos".

Após a promulgação da Constituição
Federal de 1988, que representou um marco, a dinâmica política do país sofreu uma forte influência do neoliberalismo que acabou por não efetivarem muitas das conquistas apresentadas no texto constitucional. Segundo a Comissão Pró-Índio de São Paulo a primeira iniciativaparanormatizaçãodos procedimentos de regulamentação de terras quilombolas só ocorreu em novembro de 1995, quando o Incra editou a Portaria 307, que determinava que as comunidades quilombolas tivessem suas áreas demarcadas e tituladas. Somente em novembro de 2003, devido às lutas dos quilombolas, o Presidente Lula editou o decreto $\mathrm{n}^{\circ}$. 4.887/2003 que criou as condições para a retomada das titulações, através da adoção de uma conceituação adequada de comunidade e de terra de quilombo (utilizando-se do critério da auto-identificação), além da possibilidade de desapropriação de propriedades incidentes em terras quilombolas (quando necessário) e ainda atribuiu a competência de condução do processo ao Incra.

Observa-se que o movimento quilombola, mais fortemente organizado a partir de meados da década de 90, vai consolidando uma dimensão nacional e constituindo-se num interlocutor indispensável nos antagonismos sociais que envolvem uma territorialidade diferente da dominante. Ou seja, uma territorialidade onde a propriedade privada inexiste e é valorizado o uso comum da terra, que segundo Little (2002:6) consiste "em processos sociais resultantes das contradições do próprio desenvolvimento do capitalismo", empregando uma lógica econômica específica diferente da lógica do capitalista dominante.

\section{O Quilombo São José da Serra}

O Quilombo São Jose da Serra é formado por 200 negros, a sétima geração desde os primeiros escravos comprados para trabalharem nas lavouras de café da Fazenda São José. A formação desse quilombo se deu com a abolição, quando foi doada verbalmente parte da fazendo para os então ex-escravos que construíram suas casas de adobe (tijolo de barro) cobertas de sapê, no alto da serra, à beira de um córrego.

As gerações seguintes reforçaram os laços sanguíneos e de solidariedade, sobrevivendo às muitas crises econômicas 
da agricultura, lutando pela subsistência e mantendo sua cultura. O traço marcante da cultura desse grupo é o jongo de São José que permaneceu intacto desde os tempos do Brasil colonial.

As famílias do quilombo assistiram às sucessivas gerações de herdeiros adiarem a promessa de legalização da doação verbal feita pelo primeiro proprietário. Nessas terras, os negros da São José constituíram um núcleo religioso e cultural procurado não só pelos moradores das cidades próximas, mas de vários outros pontos do Brasil e do mundo, que visitam a comunidade nos eventos que lá acontecem todo ano.

A promulgação da Constituição Federal de 1988 significou uma injeção de esperança e ânimo para os quilombolas, que passaram a lutar pelo reconhecimento como remanescente de quilombo e pela titulação das terras. No dia 05 de abril de 1999, o Governo Federal reconheceu oficialmente a comunidade como "remanescente de quilombo" abrindo caminho para a titulação de suas terras, o processo de desapropriação da fazenda mostrou-se muito demorado. Muitos quilombolas não puderam sentir o gosto de serem donos de suas terras.

A área reivindicada e com a qual têm laços históricos e memoriais, correspondem apenas à atual fazenda São José (285 hectares), enquanto a área delimitada no laudo remete toda a extensão da antiga Fazenda São José, que hoje corresponde a um conjunto de cinco grandes propriedades ( 830 hectares).

Em novembro de 2006, o Incra iniciou o processo de concessão da titulação das terras do Quilombo São José, sendo que essa concessão será maior do que a que eles vêm pedindo, compreendendo a aproximadamente 476 hectares.

\section{A Vida e o Trabalho no Quilombo São José da Serra}

A categoria trabalho tem um aspecto central na vida dos sujeitos socias, vivemos numa sociedade capitalista caracterizada pela questão social. Segundo Marx, a desigualdade na distribuição dos meios de produção faz nascerem duas classes: Trabalhadores e Capitalistas. A primeira nada tem além de sua força de trabalho para vender e a segunda é detentora dos meios de produção e do dinheiro. Os trabalhadores vendem sua força de trabalho para os capitalistas, força de trabalho que segundo Marx (1981:41) pode ser entendida como "(...) a totalidade das faculdades físicas e espirituais que existem na corporalidade, na personalidade viva dum homem e que ele põe em movimento sempre que produz valores de uso de qualquer espécie".

$\mathrm{Na}$ sociedade contemporânea, a questão social tem retornado ao centro das preocupações e sido amplamente discutida no mundo do trabalho. Observa-se hoje uma crise do trabalho e uma multiplicação e intensificação das expressões da Questão Social.

Quando pensamos numa crise do trabalho, partindo do princípio da centralidade dessa categoria na vida do homem, percebemos que ela influencia vários espaços da vida social humana, fazendo-se necessário verificar como essa crise atinge os quilombos, que são grupos com uma cultura própria, mas não isolados do restante da sociedade. Observando de perto esses grupos, fica clara a existência do hibridismo cultural, tornando-se importante verificar como a crise do trabalho e a questão social materializam-se dentro da dinâmica social dos quilombos.

Netto e Braz (2007:31) utilizamse das reflexões de Marx, definem trabalho como:

(...) um processo entre homem e natureza, um processo
em que o homem, por sua própria ação, media, regula
e controla seu metabolismo com a natureza. (...) Não
se trata aqui das primeiras formas instintivas, animais,
de trabalho. (...) Pressupomos o trabalho numa forma
em que pertence exclusivamente ao homem. (...)
O processo de trabalho (...) é a atividade orientada
a um fim para produzir valores de uso, apropriação
do natural para satisfazer a necessidade humana,
condição universal do metabolismo entre o homem e
a natureza, condição natural eterna da vida humana e,
portanto, (...) comum a todas as suas formas sociais.
(MARX, 1983 apud NETTO; BRAZ, 2007:31)

Lessa (2002) se utiliza das idéias de Lukács para demonstrar que o trabalho é a categoria fundante do mundo dos homens, deixando claro que é pelo trabalho que se efetiva o salto ontológico que retira a existência humana das determinações meramente biológicas. Com isso, podemos afirmar que só há existência social com trabalho.

As terras do quilombo são divididas entres seus moradores, sendo que algumas famílias se juntam pra fazer uma roça e 
outras cultivam suas roças sozinhas. Alguns (principalmente os aposentados) pagam para pessoas do próprio quilombo cuidarem de suas roças. $\mathrm{O}$ atual fazendeiro reduziu muito o tamanho dos quintais dos quilombolas, o que prejudicou o plantio das famílias, pois com menos terras planta-se menos e em menos variedades. Os relatos abaixo demonstram a importância do plantio para vida dos quilombolas: "Minha vida foi meio igual a da minha mãe, nunca
quis meus filhos cum fome. Só o que ganho não dá...
Precisa trabalhar pra se viver... Aí junto tudo e dá pra
viver... Planto milho, feijão, mandioca, batata e crio
porco e galinha... Não dá pra comprar tudo... Tem
que plantar para poder dar... O que colho é menos
dinheiro que gasto... Ai é que dá..."
"Quando não colhe tem que comprar tudo... ai é
difícil, mas Deus é quem sabe..."

O trabalho é visto como única opção de manter-se vivo, sendo somente através dele possível conquistar as formas de subsistência. Mesmo os quilombolas que recebem algum tipo de renda (aposentadoria e Benefício de Prestação Continuada) trabalham de alguma forma.

"Quem sempre trabalhou não agüenta parar. Sem trabalhar eu fico doente..."

“Até hoje eu trabalho... uma vida de trabalho não dá pra deitar e dormi... Deixa pra eu fazer isso depois que morrer... Enquanto der quero cuidar da minha casa e da minha roça... Você viu meus milhos... Tão lindos... Planto milho e feijão.. Criava galinha também, mas o danado do bicho de dois pé roubou tudo... Bicho de dois pé e que usa tênis ainda por cima...(muitos risos)"

"O dinheiro que ganho não dá, tenho que fazer biscates e ainda cuidar da casa. Lavo roupa, faço comida... Tem que fazer de um tudo."

Os relatos que seguem referem-se ao trabalho não só como atividade desgastante e depreciadora como também sem qualquer instância reguladora. O trabalho rural só foi regulado durante a Ditadura Militar (19641985), pela Lei $n^{0} 5.889 / 73$, regulamentado pelo Decreto $n^{\circ} 73.626 / 74$ e no artigo $7^{\circ}$ da Constituição Federal/88. A partir de 1974 foi assegurado ao trabalhador rural o rendimento de no mínimo o salário mínimo, devendo-se observar o piso salarial da categoria a que pertencer o empregado, sendo que, empregado rural é toda a pessoa física que, em propriedade rural ou prédio rústico, presta serviços de natureza não eventual a empregador rural, sob a dependência deste e mediante salário.
"Esse negócio de assinar carteira é coisa nova, na época não era costume não... Essas modernidade não era pra nois..."

"Sempre trabalhei na roça... Pros fazendeiros e pro nosso consumo mesmo... Na capina, no plantio e na colheita..."

"Meu pai não tinha saúde, mas trabalhava muito. Era enxada numa mão e os remédio na outra de sol a sol. Depois que meu pai morreu, voltei pra ficar com a minha mãe. Não era justo minha mãe ter criado tanto filho e ficar suzinha. Eu e minha mãe fomos trabalhar juntas na roça, fiz muita roça com minha mãe... Depois fiquei muito doente sabe, acho que foi a quentura da chapa da cozinha do restaurante... cozinhou eu por dentro sabe... Ai tive que operar a vesícula, fígado e os rins... Era muita quentura o dia todo e pegava bem nessa região (apontando por abdômen)."

"Trabalho desde criança como babá e doméstica.. $\mathrm{O}$ pouquinho que ganhava eu mandava pros meus pais..."

\section{Considerações Finais}

A população quilombola sempre esteve à margem de qualquer forma de cidadania, que segundo Outhwaite e Bottomore (1996:73) pode ser definida como a condição de membro de um estado-nação, sendo portador de direitos e deveres civis, políticos e sociais. A cidadania está relacionada às conquistas da classe trabalhadora, alcançada através de todo o processo histórico de lutas entre classes. Ou seja, os direitos sociais, políticos e civis, na maioria das vezes representam conquistas da classe trabalhadora, que podem ser ampliados ou reduzidos dependendo do desenrolar do processo de lutas entres as classes antagônicas.

O quilombo São José da Serra materializa-se como uma comunidade negra rural, tendo sido historicamente marginalizada e vítima dos preconceitos ligados ao meio rural e a raça negra. A luta pela titulação das terras e pelo trabalho coloca-se como ponto chave para a vida desses quilombolas, que além de terem o direito de uso da sua terra negado, sofrem por lutarem contra essa violação, tendo os seus direitos ao trabalho afetados e sendo obrigados a buscarem sua sobrevivência fora do quilombo.

Como Já foi pontuado, Marx (1983 apud NETTO; BRAZ, 2007:31) coloca o trabalho como um processo entre homem e natureza, sendo os elementos do processo de trabalho são as atividades orientada para uma finalidade, ou seja, é a atividade orientada com uma finalidade para produzir valores de uso, apropriação do natural para satisfazer a 
necessidade humana, condição universal do metabolismo entre o homem e a natureza, condição natural eterna da vida humana e, portanto, comum a todas as suas formas sociais.

Os quilombolas buscam através do seu trabalho sua sobrevivência, ou seja, eles trabalham com o objetivo de conseguir os meios para manterem-se vivos. Antigamente, quando não tinham tantas restrições e proibições quanto ao uso da terra, era possível plantar alimentos e comprar apenas itens que a natureza não fornecia tão facilmente como: querosene e sal. O trabalho para fazendeiros locais garantiam alguma renda que supria os pequenos gastos.

Com a chegada do novo fazendeiro, os quilombolas passaram primeiro a não contar com terra alguma para plantar e depois com a concessão de terras longínquas, de difícil acesso e não tão férteis. $O$ trabalho foi seriamente atingido pelo processo de titulação e pelo gado em substituição do plantio (café, milho). Nessa nova realidade adversa, o plantio persiste mais em menor quantidade e qualidade já que não há muitas terras para a atividade, o que acaba aumentando os gastos com as compras, o que não se colhe se compra.

Podemos observar que os meios de produção foram roubados dos quilombolas e seus meios de subsistir foram seriamente prejudicados, trazendo conseqüências como o esvaziamento do quilombo, os jovens aos se depararem com essa nova realidade não conseguem enxergar formas de se manterem no quilombo e acabam migrando para os centros urbanos mais próximos em busca de emprego. Os que permanecem buscam empregos como diaristas em fazendas distantes de sua residência, chegando a caminhar mais de 3 (três) horas para chegar ao trabalho.

Com seus meios de produção expropriados e as possibilidades de venderem suas forças de trabalho reduzidas, seus meios de subsistência foram prejudicados e as expressões da questão social se multiplicaram, levando os quilombolas a lutarem por seus direitos e intensificarem a prática de ajuda mútua.

Ao lutarem pelo reconhecimento enquanto quilombo e pela titulação de suas terras os quilombolas evidenciaram suas diferenças culturas frente a outros, apropriando-se de uma etnicidade própria evidenciada através do jongo, religiosidade, lido com a terra, organização, territorialidade, festividades etc.

Essa reafirmação de suas diferenças culturais aparece como importante fator para a demarcação das terras e conquista de alguns direitos de cidadania, já que há uma legislação acerca da titulação de terras quilombolas e diversos programas e políticas sociais direcionados para essa população.

O processo de titulação revela-se demorado e burocrático, não tendo ainda chegado ao seu fim e fornecido o direito a sua terra ao quilombolas e as políticas sociais e programas direcionados aos quilombolas ainda não atingiram a comunidade.

Ao pensarmos que Little (2002:3) define territorialidade como "o esforço coletivo de um grupo social para ocupar, usar, controlar e se identificar com uma parcela específica de seu ambiente biofísico, convertendo-a assim em seu "território"". Podemos perceber que os quilombolas que adotam a propriedade comum da terra, lutam hoje por sua territorialidade através do processo de titulação, num esforço coletivo da comunidade em ter a possibilidade de usar e controlar suas terras.

Com todo o exposto, podemos pensar que o quilombo São José da Serra materializase como uma comunidade negra rural, tendo sido historicamente marginalizada e vítima dos preconceitos ligados ao meio rural e a raça negra. Estudar tal comunidade revelou-se um processo rico em aprendizagem e importante para a visibilidade do duplo processo de luta dessa comunidade: Titulação de suas terras e Trabalho.

A contradição entre essas duas reivindicações coloca-se como ponto chave para a vida desses quilombolas, que além de terem o direito de uso da sua terra negado, sofrem por lutarem contra essa violação, tendo os seus direitos ao trabalho afetados e sendo obrigados a buscar sua sobrevivência fora do quilombo.

Ressaltamos o relato de uma das quilombolas que marca o âmago de toda nossa discussão: "Só as terras serem nossas não vai resolver, é preciso ter maneiras de nós nos mantermos aqui. Dar a liberdade sem trabalho não é dar liberdade."

A liberdade nesse relato refere-se à possibilidade de sobreviver com dignidade 
e autonomia, ter posse de seus meios de produção e reprodução, ter a possibilidade de viver em suas terras preservando sua cultura, afirmando sua etnicidade, desenvolvendo sua territorialidade e tendo seus direitos de cidadãos brasileiros reconhecidos e respeitados.

Ainda há muito a ser falar e analisar, foi frustrante percebermos que não poderíamos e conseguiríamos trabalhar com todos os dados colhidos na pesquisa de campo, mas acreditamos que em trabalhos futuros esses dados poderão ser analisados em sua totalidade e que a rica realidade de vida e de trabalho dessa comunidade poderá ser estudada e revelada com maior riqueza de detalhes e profundidade.

\section{Referências}

\section{ASSOCIAÇÃO DE MORADORES} DO CAMPINHO (AMOC). Quilombo Campinho. Disponível em: $<$ http://www. quilombocampinho.org/>. Acesso em: 10 Jun. 2007.

GOMES, Flávio dos Santos. Histórias de quilombolas: Mocambos e comunidades de senzalas no Rio de Janeiro, século XIX. São Paulo: Companhia das Letras, 2006.

COMISSÃO PRÓ-ÍNDIO DE SÃO PAULO (CPISP). Terras Quilombolas. Disponível em: <http://www.cpisp.org.br/comunidades/ html/i_brasil_rj.html >. Acesso em: 02 set. 2007.

IAMAMOTO, Marilda. Trabalho e Indivíduo Social. São Paulo: Cortez, 2006.

LEITE, Ilka Boaventura. Os Quilombos no Brasil: questões conceituais e normativas. Santa Catarina: NUER/UFSC, 2000.

LESSA, Sérgio. Mundo dos Homens: trabalho e ser social. São Paulo: Boitempo, 2002.

LESSA, Renato; SANTOS, Wanderley Guilherme dos. Dicionário do Pensamento Social do Século XX. Rio de Janeiro: Jorge Zahar Editor, 1996.

LITTLE, Paul E. Territórios Sociais e Povos Tradicionais no Brasil: por uma Antropologia da Territorialidade. In Série Antropologia. Brasília: UNB, 2002.

MARX, Karl. Trabalho Assalariado e Capital. 2a ed. Lisboa: 1981.

MUNANGA, Kabengele; GOMES, Nilma Lino. O Negro no Brasil de Hoje. São Paulo: Global, 2006.

NETTO, José Paulo. Cinco notas a propósito da "questão social". In: Capitalismo Monopolista e Serviço Social. José Paulo Netto. São Paulo: Cortez., 2001.

NETTO, José Paulo; BRAZ, Marcelo. Economia Política: uma introdução crítica. São Paulo: Cortez, 2007.

O'DWYER, Eliane Cantarino (Org.). Quilombos:identidadeétnica eterritorialidade. Rio de Janeiro: FGV, 2002.

PAULILO, Maria Angela Silveira. A Pesquisa Qualitativa e a História de Vida. Disponível em: <http://www.ssrevista.uel.br/c_v2n1_ pesquisa.htm>. Acesso em: 02 set. 2007.

PNUD. Relatório de Desenvolvimento Humano. São Paulo: PrimaPagina, 2005.

Endereço para Correspondência:

Profa Áurea Dias

Curso de Serviço Social

aurea.dias@foa.org.br

Centro Universitário de Volta Redonda

Campus Três Poços

Av. Paulo Erlei Alves Abrantes, $n^{\circ}$ 1325,

Três Poços - Volta Redonda / RJ

CEP: $27240-560$

Informações bibliográficas:

Conforme a NBR 6023:2002 da Associação Brasileira de Normas Técnicas (ABNT), este texto científico publicado em periódico eletrônico deve ser citado da seguinte forma:

LOPES, D.; DIAS, A.; MANSUR, D.. Trabalho e Quilombolas: As Relações de Trabalho dos Residentes no Quilombo São José da Serra - Valença/Rio de Janeiro, Volta Redonda, ano III, n. 7 , agosto. 2008. Disponível em: <http://www.unifoa.edu.br/pesquisa/caderno/edição/07/47.pdf> 